\title{
TOPOFILIA, MEMÓRIA E IDENTIDADE NA VILA DO IAPI EM PORTO
}

\section{ALEGRE $^{1}$}

\section{Letícia Maria Barbosa ${ }^{2}$}

\section{RESUMO}

O objetivo principal desta dissertação é refletir sobre as relações topofílicas na comunidade da Vila do IAPI, Bairro Passo D’Areia, Porto Alegre, RS, e efetivar um estudo de valores das ligações afetivas, ontem e hoje, com a identificação dos moradores ao lugar. As relações topofílicas foram pesquisadas através de documentos, fotos, matérias de jornais e depoimentos de moradores e ex-moradores da Vila. As coletas evidenciam as relações experenciadas no dia-a-dia dos moradores e as representações simbólicas abordadas pelo aspecto afetivo. Foram pesquisados os fatos que determinaram a expansão da indústria para a zona norte da cidade de Porto Alegre e a necessidade da criação de uma vila operária. A Vila do IAPI é caracterizada como área de interesse cultural para a cidade de Porto Alegre pela sua arquitetura e pelo seu valor histórico. Os dados coletados são mediados pela imaginação e por sentimentos e representações simbólicas na construção da cultura e identidade dos indivíduos do lugar.

Palavras-chave: geografia, topofilia, Vila do IAPI, Porto Alegre, RS

\begin{abstract}
This dissertation main objective is to think about the relationship in "Vila do IAPI" community, in Passo D'Areia neighborhood, Porto Alegre - RS, and to make a study on the values of affective connection, yesterday and today with the residents' identification to the place. The topofílica relationship was searched through documents, as photos, newspapers reports and the village residents' testimonials. The data collection shows the relationship experienced in the dáy-to-day residents' live and the symbolic representation through the affective aspect. The facts that led the industry expansion to the North area of POA were researched as well as the need of creating a workers' village. "Vila do IAPI" is known as a cultural area of interest to POA city due to its architecture and historical value, The Collected data are mediated by the imagination, feelings and symbolic representation in the culture and identity construction of the people's place.
\end{abstract}

\footnotetext{
${ }^{1}$ Dissertação de Mestrado, Programa de Pós-Graduação em Geografia/UFRGS, 2008

${ }^{2}$ UFRGS, letícia.barbosa@ufrgs.br
} 
Keywords: geography, topofilia, Vila do IAPI, Porto Alegre, RS

\section{INTRODUÇÃO}

A Vila do IAPI, localizada no Bairro Passo D’Areia, em Porto Alegre, analisada sob o prisma da Geografia Cultural, apresenta-se fundamentada pelo seu conteúdo material. Além da história de sua construção, focada no operariado, na década de 40 tem sua complexidade na própria simbologia que se desdobra em tantas outras coisas.

As mudanças ocorridas nesse lugar transformaram o cotidiano de alguns moradores mas não suas relações com o lugar. As práticas cotidianas, os sentimentos e as construções simbólicas, na Vila do IAPI, corporificados a partir das experiências e valores são elementos importantes para a compreensão de significados e representações sociais desta comunidade, relação que se dá a partir da valorização do lugar, dimensionando o ritmo com que ele se organiza.

A localização, a tipologia das moradias, o transporte; é a parte visível da constituição da comunidade. Os segmentos invisíveis são os que fornecem subsídios para chegar aos dados topofilicos.

Segundo Tuan (1974), topofilia é o elo afetivo entre a pessoa e o lugar ou ambiente físico. Difuso como conceito vivido e concreto como experiência pessoal.

O olhar dos homens sobre seu ambiente traduz suas experiências e é a partir de um referencial concreto que a totalidade simbólica da Vila do IAPI construiu sua identidade, conferindo-lhe, esta mesma identidade, status de bairro mostrando em sua estrutura a resistência em manter fatos culturais que a tornaram histórica. Nessa relação distinguem-se diferentes tipos de experiências ambientais junto às relações topofílicas em que a familiaridade e a afeição são percebidas. As pessoas investiram ali parte de sua vida emocional no transcurso do tempo.

Em Tuan (1974), a familiaridade e a afeição protegem o ser humano das perplexidades do mundo exterior. Assim como algumas pessoas são relutantes em abandonar um velho casaco por um novo, algumas pessoas, especialmente as idosas, relutam em abandonar seu velho bairro por outro com casas novas.

A Vila apresenta-se como um lugar da memória e identidade. Há a manutenção da memória e sentimento de identidade cultural, além da valorização do ambiente pela conservação das paisagens. A preservação das lembranças do passado estão contempladas na vida local da Vila do IAPI e nela os indivíduos se identificam com a história local, o cotidiano 
e as simbologias e suas instituições estão ligadas à história do lugar. A comunidade não separa da história da Vila os estabelecimentos de ensino, as quitandas, as associações, a igreja e seus seguimentos. Distingue-se no IAPI o velho e o novo, caracterizando a evolução do lugar em termos comerciais e urbanos.

Considerando que a Vila do IAPI faz parte do bairro Passo D’Areia e com ele se confunde, porquanto bairro refere-se a situação de localização, percebe-se que os espaços sociais são múltiplos e diversificados: o grupo da igreja, o grupo da bocha, o grupo da terceira idade, o grupo do futebol. Todos ao mesmo tempo diferentes e semelhantes. Nestes grupos o sentimento de vivência e de "pertença" se destacam fortemente. Os símbolos que estão incorporados à vivência e à afetividade relativas ao lugar desempenham um papel fundamental na construção da identidade da comunidade.

As experiências íntimas e diretas envolvem apreensões simbólicas. O mapa mental utilizado é o do saber vivenciado, experenciado que abrange, além da visão, as representações e interpretações do que há ao redor.

A topofilia esta presente na identificação dos moradores com o lugar e no conhecimento pessoal de cada um em relação ao que representa a Vila e a afetividade, plena de lembranças íntimas produzidas pelo meio ambiente natural, que dá sensação de abrigo.

Tuan (1974) define que a topofilia assume muitas formas e varia muito de amplitude emocional e intensidade. Certos meios ambientes naturais têm figurado de maneira proeminente nos sonhos da humanidade de um mundo ideal: a floresta, a praia, o vale e a ilha.

$\mathrm{Na}$ Vila do IAPI as pessoas percebem-se como comunidade, sendo tal fator um dos contribuintes para a afetividade. As moradias, os encontros casuais entre vizinhos e as mais variadas formas de manifestações desta comunidade expressam sua personalidade e afinidades e o fato de perceberem a Vila do IAPI não como pertencente ao bairro, mas com vida independente, reforça a cultura do lugar.

\section{A TOPOFILIA NA VILA DO IAPI}

A Vila do IAPI, situada no meio urbano, apresenta a complexidade por haver mantido ao longo dos anos o sentido de coletividade que talvez funcione como um resguardo dos desejos transitórios impostos a metrópole pela contemporaneidade.

Os moradores estabelecem a relação entre a infância vivida e as praças e áreas verdes do local. Sentem-se apegados, beneficiados e privilegiados por desfrutarem do meio ambiente que a Vila lhes proporciona. Suas visões de mundo estão representadas no simbolismo e nas 
variantes de experiências pessoais. O apego ao lugar, por ser familiar, pela natureza, por representar o passado e pela localização, é o orgulho dos moradores. Estes reforçam o sentimento topofílico através das experiências que são comuns. A percepção, a atitude e o valor que inferem ao meio ambiente mantêm suas características de visões de mundo muito semelhantes.

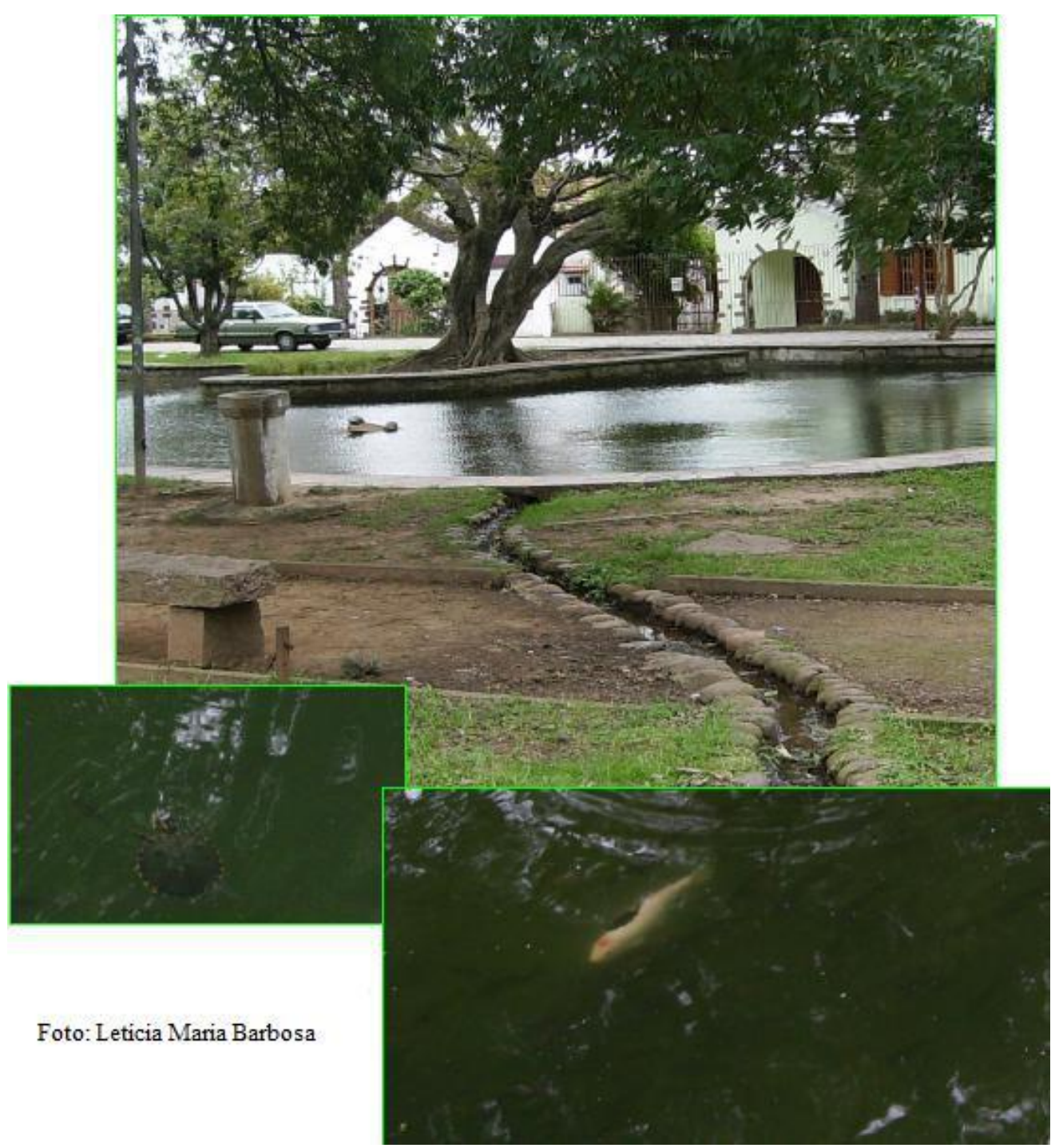

Figura 1. Praça Chopin, rua Pistóia

Claval (2001), considera que o espaço acolhe as características de um determinado tempo, assimilando-as e transformando-as sem cessar. Cada rua, bairro e cidade traz a marca de milhões de histórias que compuseram a realidade de seus habitantes, independentemente da época em que viveram.

Sob este aspecto, na Vila do IAPI cada pessoa está rodeada por camadas concêntricas, são os prédios, as casas, a vizinhança, o bairro e para além disso. O principal referencial de lugares experenciados e o habitat é a própria Vila e a rotina diária; todos são centros de significado. A realidade visível do lugar difunde, no cotidiano, elementos 
representativos do saber humano. Com isso o sentimento topofílico mitifica a Vila do IAPI, tornando-a aos olhos de quem assim a simboliza, a personificação do que há de melhor, sem considerar o que possa estar fora deste âmbito.

Cabe ressaltar que, conforme Tuan (1980), a construção do mundo ideal é uma questão de remover os defeitos do mundo real. A geografia fornece necessariamente o conteúdo do sentimento topofílico. A experiência é constituída de sentimento e pensamento. O sentimento humano não é uma sucessão de sensações distintas; mais precisamente a memória e a intuição são capazes de produzir impactos sensoriais no cambiante fluxo da experiência, de modo que poder-se-ia falar de uma vida de sentimento como se fala de uma vida de pensamento.

Resgatar o passado é compreender a história e a si mesmo, conferindo-lhes significações para o presente. As significações das atitudes e valores ambientais colaboram para a percepção de como os seres humanos respondem ao seu ambiente físico. Nesse sentido, os moradores do IAPI "sentem o lugar", tornam-no afetivo.

Segundo Tuan (1983), "sentir" um lugar se faz de experiências, em sua maior parte fugazes e pouco dramáticas, repetidas dia após dia e através dos anos. É uma mistura singular de vistas, sons e cheiros, uma harmonia ímpar de ritmos naturais e artificiais, como a hora de o sol nascer e se pôr, de trabalhar e brincar. Sentir um lugar é registrado pelos nossos músculos e ossos.

Acontecimentos marcantes na vida dos indivíduos levam-nos a relacionarem os acontecimentos com a localidade (característica muito comum entre os entrevistados) e a afetividade, algumas vezes, aparece ligada ao tempo de vivência no lugar, considerando-se no ciclo da vida humana o "olhar pra trás", que, além de conter carga emotiva, dá sentido à identidade do "eu".

O IAPI entrou para a história da habitação popular como uma experiência exemplar porque não se limitou a oferecer quatro paredes aos associados do Instituto de Aposentadoria e Pensões dos Industriários, mas iluminação solar satisfatória, ventilação agradável e diferentes modelos e tamanhos de casas e prédios (Zero Hora, sábado, 4 de dezembro de 1993).

Resgatando a história da Vila do IAPI percebemos que a Vila apresenta-se fundamentada pelo seu conteúdo material. O mapa mental da representação do lugar constituise das representações espaciais do espaço vivido no cotidiano, seja no presente ou no passado, formadas a partir de acontecimentos sociais, culturais, históricos, econômicos ou divulgados nos meios de comunicação. 
Encontro trata da Vila no Plano Diretor. A comunidade da Vila do IAPI voltará a se reunir hoje com o vereador Sebastião Melo e representantes do Executivo Municipal. A reunião começa às 20h, na sede da Associação dos Moradores da Vila do IAPI (Amovi), localizada na avenida dos Industriários, 433, na Capital. Os encontros vão debater a Vila do IAPI no contexto do Plano Diretor. Esta será a terceira reunião dos moradores com o vereador, que está aprofundando as discussões. Recentemente, foi realizada uma caminhada pelo núcleo onde foram analisadas as possibilidades de flexibilização, de conservação e de revitalização do conjunto residencial, que está incluído na área de interesse cultural de Porto Alegre. A cidade de Porto Alegre tem tradição em planejamento urbano, constituindo-se na primeira Capital do País a contar com um Plano Diretor. No início do século surgiu a primeira tentativa de organizar o crescimento da cidade, com o arquiteto João Moreira Maciel propondo o "Plano Geral de Melhoramentos", que data de 26 de agosto de 1914. Apesar de ser um plano tipicamente viário, estava calcado em princípios orientadores bem definidos. (23 de abril de 2007/Correio do Povo).

A Vila, afetivamente lembrada não só por seu projeto arquitetônico bem sucedido, mas também por motivos que a tornaram popular, mantém-se viva na memória de moradores e simpatizantes pela música, pelo concurso Rainha dos Industriários, pela Escola de Samba União da Vila do IAPI e, é claro, por sua moradora mais ilustre, Elis Regina.

Conforme Tuan (1980), para compreender preferência ambiental de uma pessoa, necessitaríamos examinar sua herança biológica, criação, educação, seu trabalho e os arredores físicos. No nível de atitudes e preferências de grupo, é necessário conhecer a história cultural e a experiência de um grupo no contexto de seu ambiente físico. Os conceitos "cultura" e "meio ambiente" se superpõem do mesmo modo que os conceitos "homem" e "natureza".

Notadamente, em nosso estudo, os entrevistados atentam para a espacialização, dimensionando aquilo que percebem e reconhecem em seu entorno. Reconhecem muito mais cada parte da Vila do IAPI do que do bairro do qual eles propriamente fazem parte (Passo D’Areia). 
A relação de afetividade apresenta-se em suas falas, ao se reportarem a símbolos que representam a Vila, como a estátua da Índia Obirici (que dá nome também ao viaduto), o Estádio Alim Pedro, a Igreja Nossa Senhora de Fátima. Comentam o cotidiano como se estes lugares a que se referem fossem lugares conhecidos por outras pessoas:

“(...) fui ali no Alim Pedro..(...).”; “(...) ah, lá no laguinho acontecia o encontro das bandas pro futebol (...).” - Edison de Lima Espíndola - Edinho -, da Banda de Rock Liverpool.

A afeição, familiaridade e intimidade com estes lugares e símbolos dão a sensação de serem pertencentes ao lugar e de que esse lugar lhes pertence. A consciência do passado torna-se um elemento importante no amor pelo lugar. Os indivíduos pensam em si mesmos como membros de uma coletividade em que os símbolos expressam valores e, a partir disso, criam uma memória comum voltada para a simbologia, enaltecendo e classificando-a como o melhor lugar para se viver:

"(...) eu não me sinto saído da Vila, ali é sempre a minha volta (...)” Edison de Lima Espíndola - Edinho -, da Banda de Rock Liverpool.

“(...) é um dos melhores bairros de Porto Alegre (...) dificilmente vão fazer um complexo como aquele (...).” Nilson Guedes - Fundador da Escola de Samba União da Vila do IAPI.

Haesbaert (1999), ao tratar da questão da identidade social, reforça que identificar, no âmbito humano-social, é sempre identificar-se, um processo reflexivo, portanto, e identificar-se é sempre um processo de identificar-se com, ou seja, é sempre um processo relacional, dialógico, inserido numa relação social. Além disso, como não se encara a identidade como algo dado, definido de forma clara, mas como um movimento, trata-se sempre de uma identificação em curso, e, por estar sempre em processo/relação, ela nunca é una, mas múltipla.

Alguns se referem à Vila como se a representassem: minha vila. A identificação dos moradores com o lugar confere-lhes poder e posse sobre os símbolos que o representam e que recebem outros tantos significados.

Em Tuan (1974), o lugar ou o meio ambiente são produtores de imagem para a topofilia, pois esta é mais que um sentimento difuso, sem nenhuma ligação emocional. $\mathrm{O}$ meio ambiente fornece o estímulo sensorial que, ao agir como imagem percebida, dá forma às nossas alegrias e ideais. 
“(...) da minha infância, me recordo dos dias em que meu pai me acompanhava aocampo Alim Pedro para andarmos de regata ( brinquedo construído com madeiras que deslizava pela grama). Ao cruzar o campo, me lembro dos dias da minha infância.

Gostaria de mostrar a meus filhos esta brincadeira (...)” - Leonardo Barbosa, morador.

Conforme Tuan (1974), estímulos sensoriais são potencialmente infinitos: aquilo a que decidimos prestar atenção (valorizar ou amar) é um acidente do temperamento individual do propósito e das forças culturais que atuam em determinada época.

“(...) lembro dos parques de diversão que se instalavam no Alim Pedro, do carnaval na Avenida dos Industriários, das festas juninas com fogueiras. (...)” - Márcia Pinto, moradora.

Através do conceito de topofilia ou elo afetivo entre o sujeito e o espaço, bem como entre o sujeito e os demais sujeitos no espaço em questão, Tuan (1980) afirma ser essa relação o determinante de valor atribuído ao espaço, quando há: diferença entre a visão do visitante e a do morador de determinado espaço, meramente estético pelo primeiro e mais abrangente pelo segundo; constância entre os grupos socioculturais em conceberem o mundo e o cosmos a partir de um referencial etnocêntrico, superestimando seus lugares como centrais e ideais; as visões de mundo peculiares que se "constroem" pelos grupos socioculturais que vivem em determinados ambientes ou habitats humanos.

“(...) existem muitos moradores antigos, criando-se, desta forma, uma comunidadefechada (...) a maioria das famílias são conhecidas de muito tempo, tem-se um convívio muito estreito, pode-se dizer que é uma grande família (...)” - Leonardo Barbosa, morador.

O orgulho que os moradores demonstram ao reconhecerem na Vila a história de si mesmos inclui os laços afetivos de suas bagagens de vivência na construção de suas trajetórias individuais e do seu dia-a-dia. Muitas destas pessoas trazem a marca de épocas em que acontecimentos e símbolos ficaram registrados, impregnados no ambiente e na memória como sensações agradáveis e nostálgicas do cotidiano que muitas delas até hoje experimentam.

“(...) lembro de nossas mães, muitas vezes, brincando como se fossem crianças (...) elas andavam de balanço... brincavam de roda (...)” - Leilane Gaspary, moradora.

“(...) lembro que, quando eu era pequena, brincava na rua de esconde-esconde, tomava banho de chuva (...) este local é calmo.(...)” - Marrogani Soares, moradora. 
“(...) para mim, a nobreza do IAPI está na riqueza da sua história, na beleza das suas ruas, na arborização, no contraste entre o velho e o novo, da riqueza de ter idosos passeando pelas ruas e contando seus 'causos antigos' (...).” - Maria Cristina Soares, moradora.

Segundo Tuan (1983), o lugar é o espaço que se torna familiar às pessoas, consiste no espaço vivido da experiência. Como um mero espaço se torna um lugar intensamente humano é uma tarefa para o geógrafo humanista, para tanto, ele apela a interesses distintamente humanísticos como a natureza da experiência, a qualidade de ligação emocional dos objetos físicos às funções dos conceitos e símbolos na criação de identidade do lugar.

Os laços de afetividade que ligam o homem, abstrata ou concretamente, ao lugar vivido despertam sentimentos e provocam relatos e referências verbais e/ou escritas de poetas, intelectuais e mesmo cidadãos comuns, os quais buscam evocar a alma dos lugares, captam e descrevem o desempenho dos seres humanos, a fixação aos lugares, o cotidiano, o transcendental, a nostalgia, enfim uma gama ampla de motivos e emoções.

“(...) para mim, o grande diferencial do Passo D’Areia é a Vila do IAPI e, fora aarquitetura do conjunto ser diferenciada e única, também tem o tipo de relação de vizinhança e companheirismo que ali se criou. (...)” - Luiz Antonio Pereira, ex morador.

Tuan (1974) considera que a topofilia não é a emoção humana mais forte. Quando é irresistível, pode-se estar certo de que o lugar ou meio ambiente é o veículo de acontecimentos emocionalmente fortes ou é percebido como um símbolo.

As mudanças ocorridas neste lugar, mesmo sendo ameaçadores à vida social de seus habitantes, estão engessadas pelas lembranças afetivas do passado, influenciadas fortemente pelas imagens ideais construídas pelos moradores, porquanto, na Vila do IAPI as pessoas percebem-se como comunidade, sendo tal fator um dos contribuintes para a afetividade. As moradias, os encontros casuais entre vizinhos e as mais variadas formas de manifestações desta comunidade expressam sua personalidade e afinidades.

A familiaridade com que os moradores descrevem o lugar faz com que símbolos bastem como referência. "Vou ali no Obirici," já identifica que a pessoa vai até o comércio da Avenida Assis Brasil. "Vou lá no Seu Batista", identifica o mercadinho da esquina da Rua Santiago. "Fui à Fátima", identifica que esteve na Igreja Nossa Senhora de Fátima, localizada na Rua Rio Pardo. "Moro na rua do Becker", identifica que mora na Rua Nova Prata, onde está localizado o Colégio Estadual Dom João Becker . 
As experiências íntimas e diretas envolvem apreensões simbólicas. O mapa mental utilizado é o do saber vivenciado, experenciado que abrange, além da visão, as representações e interpretações do que há ao redor.

“(...) não é à toa que até hoje resistem e sobrevivem pontos comerciais dirigidos ouatendidos pela segunda e até terceira geração de proprietários do mesmo negócio. Leiteria da Fiorina, o Bar 44, a foto Nick (...)” - Luiz Antonio Pereira, ex morador.

Ao tratar a Vila do IAPI como lugar, expressa-se a força que induz esta classificação por sua história, as coisas impregnadas a ela e estendidas aos sujeitos que ocupam este lugar, estabelecendo uma relação de valorização e pertencimento. Compreende-se o lugar como algo inacabado e que está num processo de constante alteração, aberto e em movimento. Daí, a necessidade de ampliar o entendimento do vivido para o concebido.

Tuan (1983) analisa as diferentes maneiras como as pessoas sentem e conhecem o espaço e o lugar e salienta como o homem experencia e entende o mundo. Para ele, lugar é segurança, é também a liberdade que o indivíduo sente quando se apega ao lugar. Afirma que o lugar se singulariza a partir de visões subjetivas vinculadas a percepções emotivas, a exemplo do sentimento topofílico (experiências felizes).

“(...) foi uma infância de muitas lembranças felizes e determinantes para minha visão de mundo (...)" - Luiz Antonio Pereira, ex morador.

Na Vila do IAPI cada pessoa está rodeada por camadas concêntricas, são os prédios, as casas, a vizinhança, o bairro e para além disso. O principal referencial de lugares experenciados e o habitat é a própria Vila e a rotina diária; todos são centros de significado.

O comportamento identitário dos moradores ao lugar, analisado sob o aspecto sócio espacial, é caracterizado pelas imagens desse lugar. Com base neste aspecto, os objetos do cotidiano, os movimentos culturais e a paisagem determinam a construção social de identidade da Vila e relacionam-se ao indivíduo no âmbito pessoal e também ao indivíduo e à coletividade, propiciando fenômenos sociais em cada grupo, seja o da cancha de bocha, o da terceira idade, o da igreja ou o do esporte.

Estabelece-se no mesmo espaço a identidade territorial definida através da apropriação de idéias mais ou menos comuns e com valores simbólicos que se apresentam de maneira diferente, dependendo da idade cronológica de cada grupo, da época e do lugar.

“(...) houve uma época em que os fatos e as fotos das famílias circulavam pela Vila. $A$

comunidade participava de eventos dos vizinhos mais próximos (...). Casamentos, quinze anos, formaturas...era tudo de bom(...)”. Heloisa Pereira, moradora. 
“(...) recordo muito dos desfiles escolares no 7 de Setembro, que reunia as escolas do

bairro;desfile de escolas de samba no fim da noite, onde todos que participavam divertiam-se muito (...)” - Iracema Angelos, ex moradora.

A identidade é construída a partir de subjetividades individuais e coletivas. Os simbolismos deste lugar contribuem enormemente para a incorporação de sua memória, carregado-o de valores e sentidos que se apresentam como suporte essencial para a ligação emocional e topofílica.

“(...) éramos pobres, mas tínhamos muita alegria (...) nas vendas lembro que o atendimento era pessoal e muito amigável, todos se conheciam e tinham crédito na vendinha, no alto, bem acima da Escola Gardolinski (....)". - Tânia Elizabeth Ferreira, ex-moradora.

O lugar ou o meio ambiente são produtores de imagem para a topofilia, pois esta é mais que um sentimento difuso, sem nenhuma ligação emocional. O meio ambiente fornece o estímulo sensorial que, ao agir como imagem percebida, dá forma às nossas alegrias e ideais. (TUAN 1974: 129)

Resgatar o passado é compreender a história e a si mesmo, conferindo-lhes significações para o presente. As significações das atitudes e valores ambientais colaboram para a percepção de como os seres humanos respondem ao seu ambiente físico.

Tratando a Vila do IAPI com o termo "lugar" que, conforme Tuan (1893), indica experiência comum, relaciona-se a topofilia aos significados e experiências compartilhados por uma comunidade de pessoas que respondem a este lugar com pensamentos e sentimentos que transcendem as particularidades culturais.

A afetividade, algumas vezes, aparece ligada ao tempo de vivência no lugar, considerando-se no ciclo da vida humana o "olhar pra trás", que, além de conter carga emotiva, dá sentido à identidade do "eu".

“(...) o campo era minha floresta... a liberdade dentro do IAPI (...) aquilo ali não tem preço (...) me tornou um cara 'relax' pronto pra enfrentar tudo”. Edison de Lima Espíndola Edinho - da Banda de Rock Liverpool.

O sentimento topofílico mais aguçado e a relação de pertencimento mais consolidada se dão nos diálogos de moradores nos estabelecimentos urbanos locais. Há um conhecimento preciso sobre a vizinhança e as imediações. Fatores tais como cultura, sexo e idade fazem parte das multirrelações do processo de percepção ambiental.

A apreciação da paisagem é mais pessoal e duradoura quando se manifesta mesclada com incidentes humanos e lembranças, perdurando além do efêmero. Surgindo como um 
envolvimento suave, inconsciente com o mundo físico, tais relações sociais engendram afeição ou desprezo, uma vez que os lugares e sentimentos são uma extensão da personalidade e caracterizam a identidade. A própria cultura não pode ser separada do meio ambiente.

“(...) os carnavais que tinham aqui, fazíamos merenda (...) tenho uma visão assim: parece um sonho (...) olho agota e não acredito que a gente caminhava na rua, era uma coisa diferente, inexplicável (...) como vou te dizer (...) o desfile de Sete de Setembro, aquilo pra mim era tudo (...) o desfile na Industriários, na frente do campo, era coisa mais linda (...) a Vila é mais que Elis Regina (...)” - Ana Maria Silveira Soares, moradora.

A consciência do passado é um elemento importante no amor pelo lugar, encarada como herança, um legado a ser preservado, algo que enraíza os sentimentos, uma memória que pode ser tanto individual quanto social e reaparece nas relações pessoais com a simbologia do espaço vivido.

“(...) existia a vertente que ficava na confluência da Rua Pistóia e da Rua João Moreira Alberto (...) era muito bonito! A água descia entre as pesdras (...) havia o caminho beirando o lago (...) tinha girino de montão (...) bons tempos! (...)” - Tânia Lago, exmoradora.

Tais laços de afetividade que ligam o homem, abstrata ou concretamente, ao lugar vivido despertam sentimentos e provocam relatos e referências verbais e/ou escritas de poetas, intelectuais e mesmo cidadãos comuns, os quais buscam evocar a alma dos lugares, captam e descrevem o desempenho dos seres humanos, a fixação aos lugares, o cotidiano, o transcendental, a nostalgia, enfim uma gama ampla de motivos e emoções.

$\mathrm{Na}$ Vila do IAPI, lugar totalmente integrado à malha urbana da cidade, percebe-se um ambiente de construções isoladas e de densa vegetação. A permanência de características originais em termos de tipologia arquitetônica e morfologia urbana valeram seu reconhecimento como área de interesse cultural da cidade de Porto Alegre.

A dicotomia no entorno da Vila é visível. O urbano mistura-se às áreas verdes. Os moradores circulam em espaços públicos abertos caracterizados pela grande movimentação de pessoas e automóveis como também desfrutam de áreas mais tranqüilas inseridas no "centro" da Vila, mais precisamente localizadas nas proximidades do Estádio Alim Pedro.

A Viela São Braz, arborizada, com praças e prédios ornamentados com arcos, localizada próximo a Avenida Plínio Brasil Milano, avenida de grande fluxo para o centro da cidade, com prédios antigos da construção do IAPI de um lado e prédios contemporâneos do outro, além do comércio, demonstra o dualismo, simbolizando os opostos. Dois momentos refletem a natureza e os aspectos da vida das pessoas que transitam nestes lugares tão 
próximos e tão distantes ao mesmo tempo. A natureza mostra um meio nitidamente diferenciado, dividido entre o ambiente da vila, densamente arborizado, e os "espigões" localizados nas Avenidas Assis Brasil e Plinio Brasil Milano.

Conforme aborda Fischer (s/d), uma forma de compreender a relação no espaço ocorre a partir da maneira como o homem utiliza um lugar, como o trata afetiva e cognitivamente. Trata-se de um espaço vivido, ou seja, investido por uma experiência sensório motora, tátil, visual, afetiva e social que produz, através das relações estabelecidas com ele, um conjunto de significações carregadas de valores culturais próprios. A relação do espaço arquitetônico não se reduz às suas propriedades materiais: ei-lo estruturado como uma linguagem que comunica uma mensagem sobre os seus ocupantes, sobre suas funções; um edifício será então apreendido e avaliado como a encenação de uma espécie de biografia social de uma instituição e dos habitantes que ocupam, do bairro em que se situa.

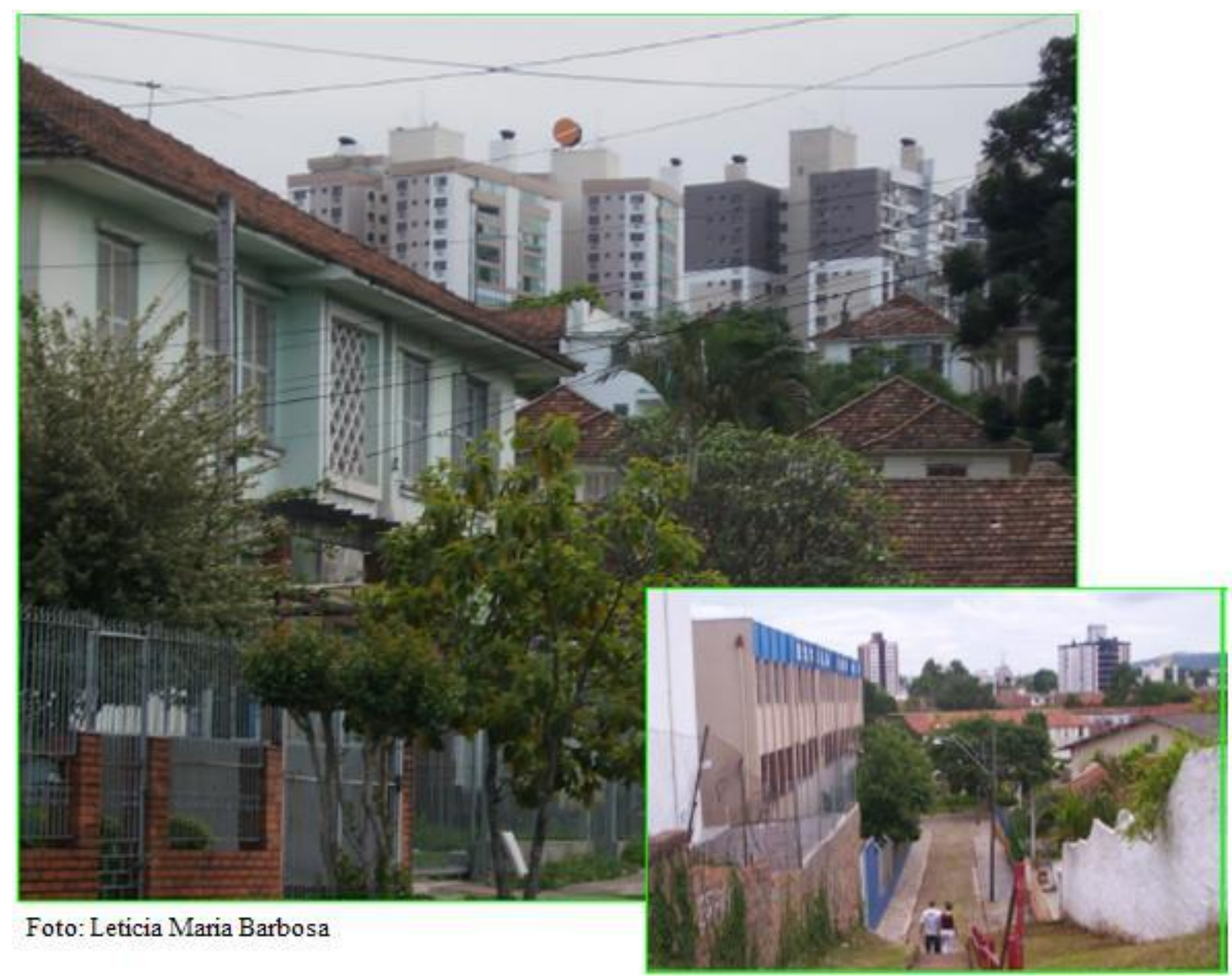

Figura 2. Viela São Braz, contraste entre o velho e o novo

Um efeito do meio ambiente que percebe-se estar presente no IAPI é a vegetação. Em cada quadra ou rua, a vegetação está muito próxima dos moradores. Esta visão reforça o 
oposto que circunda a Vila, parecendo estar dividida entre a densa arborização e os prédios das avenidas Assis Brasil e Plínio Brasil Milano, lugares de intenso movimento urbano.

Os lugares de lazer e áreas verdes da Vila do IAPI, viabilizados desde a sua construção, geraram paisagens autênticas e possibilitaram a conexão entre as pessoas , o lugar e a natureza. As mudanças ocorridas neste lugar, mesmo sendo ameaçadores à vida social de seus habitantes, estão engessadas pelas lembranças afetivas do passado,influenciadas fortemente pelas imagens ideais construídas pelos moradores .

Tuan (1983) afirma que na relação de tempo e lugar é evidente a necessidade de considerar o ciclo da vida humana. O que significa o passado para nós? As pessoas olham para trás por várias razões, mas uma é comum a todos: a necessidade de adquirir um sentido do eu e da identidade.

O sentimento incorporado à cultura local contribui para a formação da identidade da Vila e este sentido de identidade envolve satisfação, percepção, felicidade e o simbolismo que é o somatório das experiências para esta construção.

Para Fischer (s/d), um espaço conta sempre uma história: individual e social; diz do grupo ao grupo qual é a sua maneira de viver, de habitar, de trabalhar, de viver socialmente num lugar. A compreensão da relação no espaço como experiência vivida traz um esclarecimento complementar, mostrando que os lugares estão carregados de significados ligados às representações sociais que deles se fazem.

A complexidade ambiental e o valor simbólico do IAPI levam a discussões no âmbito de renovação e conservação dos espaços urbanos da cidade de Porto Alegre que visam a melhoria das áreas de integração das comunidades.

A dicotomia, no sistema viário da malha urbana das proximidades da Vila do IAPI e os elementos arquitetônicos construídos na primeira metade do século $\mathrm{XX}$, ainda compõem a estrutura da cidade contemporânea, juntamente com construções mais recentes.

Considerada por muitos como Patrimônio Cultural da cidade de Porto Alegre, indica, pela sobrevivência e conservação, por sua importância enquanto imaginário urbano, atuando como referência de qualidade ambiental e identidade coletiva supomos que se assim é qualificada deverá estar iluminando novos projetos de construção da cidade do presente e do futuro. 


\section{BIBLIOGRAFIA}

BACHELARD, G. A poética do espaço. Tradução de António Danesi. Ed. Martins Fontes. São Paulo. 1989. 149 pp.

BARBOSA, Letícia M. A topofilia na Vila do IAPI em Porto Alegre. Dissertação (Mestrado em Geografia) - Universidade Federal do Rio Grande do Sul, Porto Alegre, 2008, $120 f$.

BONDUKI, Nabil. Origens da habitação social no Brasil. Aquitetura moderna, Lei do Inquilinato e difusão da casa própria . São Paulo: Estação Liberdade, Fundação de Amparo à Pesquisa do Estado de São Paulo, 1998. p. 132-177.

CLAVAL, P. O papel da nova Geografia Cultural na compreensão da ação humana: In: ROSENDAHL, Z.; CORRÊA, L.R. (Org.) Geografia Cultural, matrizes da Geografia Cultural. Rio de janeiro: Editora da Universidade do Estado do Estado do Rio de Janeiro, 2001. p. 35-80.

DEGANI, José Lourenço. Tradição e modernidade no ciclo dos IAP's. $O$ Conjunto Residencial do Passo D'Areia e os projetos modernistas no contexto da habitaçãopopular dos anos 40 e 50 no Brasil. 2003. Dissertação (Mestrado em Aqruitetura) - Universidade Federal do Rio Grande do Sul, Porto Alegre, 2003. 177 f.

FAYET, Carlos M. (Coord.) Vila do IAPI, patrimônio cultural da cidade. Porto Alegre: Prefeitura Municipal de Porto Alegre, 1994

FISCHER, Gustave-N. Psicologia social do ambiente. (Perspectivas Ecológicas):Instituto Piaget. (1994). p. 23-41.

HAESBAERT, R. Identidades territoriais. In: ROSENDAHL, Z.; CORREAA, L. R. (Org.) Geografia Cultural, manifestações da cultura no espaço. Rio de Janeiro: Editora da Universidade do Estado do Rio de Janeiro, 1999. p.169-188.

MENEGAT, Rualdo; PORTO, Maria Luiza; CARRARO, Clóvis Carlos; FERNANDES, Luís Alberto D’Ávila. Atlas ambiental de Porto Alegre. Porto Alegre:Editora da Universidade/Universidade Federal do Rio Grande do Sul, 1998. p. 140.

TUAN, Yi-Fu. Topofilia: um estudo da percepção, atitudes e valores do meio ambiente.São Paulo: DIFEL, 1974. 288 pp.

TUAN, Yi-Fu. Espaço e lugar: a perspectiva da experiência. São Paulo: DIFEL, 1983. 250 